\title{
Article
}

\section{Selective Use of Corn Crop Residues: Energy Viability}

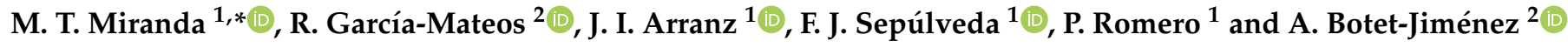 \\ 1 Department of Mechanical, Energy and Materials Engineering, Industrial Engineering School, University of \\ Extremadura, Av. Elvas s/n, 06006 Badajoz, Spain; jiarranz@unex.es (J.I.A.); fsepulveda@unex.es (F.J.S.); \\ pmunoz@unex.es (P.R.) \\ 2 Scientific and Technological Research Centre of Extremadura (CICYTEX), C/Pamplona 64, \\ 06800 Mérida, Spain; raquel.garcia@juntaex.es (R.G.-M.); almudena.botet@juntaex.es (A.B.-J.) \\ * Correspondence: tmiranda@unex.es
}

check for updates

Citation: Miranda, M.T.

García-Mateos, R.; Arranz, J.I.; Sepúlveda, F.J.; Romero, P.; Botet-Jiménez, A. Selective Use of Corn Crop Residues: Energy Viability. Appl. Sci. 2021, 11, 3284. https:// doi.org/10.3390/app11073284

Academic Editor: Francisco Heras

Received: 17 March 2021

Accepted: 31 March 2021

Published: 6 April 2021

Publisher's Note: MDPI stays neutral with regard to jurisdictional claims in published maps and institutional affiliations.

Copyright: (c) 2021 by the authors. Licensee MDPI, Basel, Switzerland. This article is an open access article distributed under the terms and conditions of the Creative Commons Attribution (CC BY) license (https:/ / creativecommons.org/licenses/by/ $4.0 /)$.

\begin{abstract}
The corn crop is one of the most important crops worldwide. However, the management of the residues generated is not efficient enough, which diminishes the competitiveness of this crop. An interesting option for the valorization of these wastes is their thermal use. In order to make the management of this residue as much efficient as possible, it is vital to know the different processes related to a corn harvest, and try to adapt the use of this waste depending on its characteristics. Thus, in this work, and on the basis of a conventional corn harvest, a differentiated analysis of the residue generated was carried out, including its characterization and assessing its behavior during pyrolysis and combustion. The results pointed out the importance of collecting residue immediately after its generation and avoiding its contact with the soil as this factor tends to worsen its thermal properties and ash content. Concerning the selective collection, it is highly advisable if the subsequent thermal use is going to be a pyrolytic process. In the case of combustion, even though the samples that contain corn stalk showed better combustion properties, this improvement did not outweigh the adverse effects related to the increase in ash content, especially for its pelletizing.
\end{abstract}

Keywords: zea mays; agricultural waste; biomass; physicochemical properties; thermogravimetric analysis

\section{Introduction}

Currently, corn is one of the major global crops, along with other cereal crops like wheat or rice, being an essential source of food for humans. According to the Food and Agriculture Organization (FAO), the world production of corn has recently increased until 2018, where the production decreased by 1.31\%, compared to 2017 [1].

If the situation of corn crops in Spain is considered, according to the FAO, it is one of the ten most important crops in this country. However, there has been a decrease both in production and in the cultivated area since 2013. In 2013, there was a harvested area of 442,300 hectares and a production of 4885 million tons, whereas in 2018, the harvested hectares were 322,373 and the production was 3842 million tons [1], which has implied a $21.35 \%$ decrease in five years. The low market prices, as well as other secondary factors, such as high water use, several pests or high international competition, have made this crop less attractive for Spanish growers.

In a corn crop, a residue called corn stover, which is mainly composed of different parts of the plant like corn stalk, leaves and corncob waste, is produced. Currently, these wastes are left on the soil, being mechanically ground in order to be mixed with the soil after harvest. To a lesser extent, these wastes are used to produce bales to be used in biomass power plants or for livestock purposes. Formerly in Spain, corn stover was usually burned in the country, with the associated environmental risk and impact. Fortunately, this practice is in disuse.

Concerning the production of corn stover generated during the corn harvest, Azuara et al. [2] established that the proportion of corn stover produced per corn plant (dry basis) was 0.65 , 
whereas Zheng et al. [3] showed a corn stover ratio of 0.86; according to this data, and considering an average moisture of 20\%, the production of corn stover in Spain in 2018 would be 1997 million tons and 3304 million tons, respectively. As it can be observed, different references showed disparate results about corn stover production, as its generation is dependent on the kind or variety of corn, the way of harvesting, the subsequent use of this crop and the area where the corn is grown, among other factors [2,3]. In any case, the amounts of corn stover produced are significant enough to justify a study about the treatment of this waste for the competitiveness and economical improvement of corn crops.

The harvesters, currently used in corn crops, usually cut and separate the corn grain, placing it in a hopper. The corncob waste and stalks come out, separately, from the rear of the harvester, although both parts are released jointly and remain on the soil. In order to transform this waste into bales, a previous swath process is necessary, followed by a baling process. Swathing can be carried out by the same harvester by incorporating a specific device or, at a later time, using other machinery. Afterwards, baling is carried out, which implies a partial soil dragging, increasing the proportion of impurities in the bale produced. As it was previously pointed out, swathing is, in many cases, a discontinuous process, existing for the period (even for several days) when the residue remains on the soil. In addition, bales are not immediately collected after their generation. Both periods can imply a degradation of this residue, due to weather conditions, which could limit its subsequent use. According to the literature, another study has reported other harvest systems that allows for the collection of corn stover before its contact with the soil, through a rolling system of wastes [4]. In any case, this system would not avoid the deterioration of bales due to their stay on the soil for several days, which will depend on the time of collection for their subsequent use. Thus, the baling system is not always economically profitable for corn growers as, on one hand, it implies an additional cost and, on the other hand, the profits are not competitive.

In order to obtain a competitive improvement in corn crops, thereby increasing the profits of growers, it is interesting to conduct the search for added value of the residues generated. One of the possible applications of these wastes is their energy use. Biomass from agricultural practices is mainly composed of hemicellulose (20-30\%), cellulose (40-50\%), lignin (10-25\%) and other organic compounds [5]. Regarding corn stover, the percentages for the corncob waste are 35\% hemicellulose, $45 \%$ cellulose and 15\% lignin [6] and for corn stalk these percentages are $26.45 \%$ hemicellulose, $36.43 \%$ cellulose and $27.33 \%$ lignin [7], which indicates that corn stover could be used as biomass.

Among the different thermal processes of biomass, pyrolysis and combustion two simple and direct processes for energy extraction from biomass are considered [8], as well as two essential procedures for the study and control of thermal processes that are developed during biomass conversion. For the study of thermal processes, thermogravimetric analysis (TG) is a basic tool, as it can assess the suitability of corn wastes as biofuels as well as it can determine the thermal process with the best performance. The main conclusions about the use of these residues as fuels can be inferred through the comparison of the results obtained with thermogravimetric results of other biomass samples currently used.

Concerning the use of biomass, one of the ways to generate thermal energy is through pellet combustion, as it is considered an ecological fuel and classified as a biofuel with zero-net $\mathrm{CO}_{2}$ emissions [9]. Its use can be industrial (for drying or steam production) or domestic (for heating or hot water production). Pellets show better characteristics than other biomass products like chips or briquettes, due to their higher density and consistent granulometry, which allows for automatic feeding in biomass boilers [10]. For this reason, pellet production is considered a promising and profitable market in Spain.

So far, different studies about the energy use of corn residues have been published. Chen et al. [7], Shen et al. [8], and Zhang et al. [11] carried out the thermogravimetric analysis of corn stalk. Similarly, Aboyade et al. [12], Yang et al. [13] and Maddei et al. [14] carried out the thermogravimetric study of the corncob waste. Other articles have studied the pyrolysis of the complete corn stover $[15,16]$. Concerning the separate study of this 
waste, Li et al. [17] carried out a thermogravimetric study of the pyrolysis of different parts of corn, such as corn stalk skins, corn stalk scores, corn bracts and corn leaves. Regarding thermogravimetric studies in combustion processes, different references were found, specifically about corn stalk [8] and corncob waste [18], separately.

According to previous studies, a comparison of different wastes of corn is considered in the present article, such as the following: complete corn waste, stover, and different wastes that could be classified depending on the collection system of corn harvest (which generates stalk and corncob waste). So far, all the works carried out studied the wastes separately, according to their physical or morphological characteristics, whereas in this study, the separation of wastes depending on the collection system will prevail, so that the valorization of wastes can be easier without any additional complication during harvesting. Moreover, taking into account that ash content is one of the most important parameters to determine the quality of a biofuel after combustion [19]; the effect of the collection of corn residues on ash production was studied, as a negative effect is possible due to the contact of the wastes with the soil. This is the case of stover baling, where the waste is placed on the ground for a certain period of time before it is baled, dragging and adding some land in the final bale, which implies an increase in impurities in the residue.

To sum up, the aim of this study was, firstly, to research the pyrolysis and combustion of different corn residues, paying attention to the conventional collection system. Thus, the joint collection of corn stover and the separated collection of the different by-products of corn stover (like corncob waste and corn stalk) were considered, in order to determine the most suitable waste for thermal use. Secondly, a study of the positive effect of the direct collection of wastes from the harvester (without any contact between the residues and the soil) was considered, as it is possible that this contact implies a degradation of the wastes. Thirdly, and regarding the results obtained from the study of pyrolysis and combustion, the selection of the most suitable waste collection, as well as the possible interest of a selective collection of them, was considered. Considering the above, the final aim of this study was to add value to the corn crop through the thermal use of its wastes in different ways: as biofuels to produce pellets for domestic or industrial use, for direct electricity production or any other thermal use that can imply a valorization of corn crops.

\section{Materials and Methods}

In the following sections a description of the different wastes studied, as well as the different tests used in the present work, are included.

\subsection{Sample Collection and Preparation}

\subsubsection{Sample Collection Process}

For the development of the present study, different wastes from corn were selected, which were collected from local crops in the southwest of Spain.

Currently, harvesters carry out a separation of corncob from the stalk. Therefore, it would be interesting to compare both wastes separately, that is, on one hand, corncob waste with the leaves that cover the corncob and, on the other hand, corn stalk with leaves. Equally, it is interesting to compare the characteristics of the corncob waste with and without leaves, in order to assess the effect of leaves on thermal properties of this waste, as separation would be a process with an easy implementation. The corn harvest system, as well as the different residues generated, is included in Figure 1. 


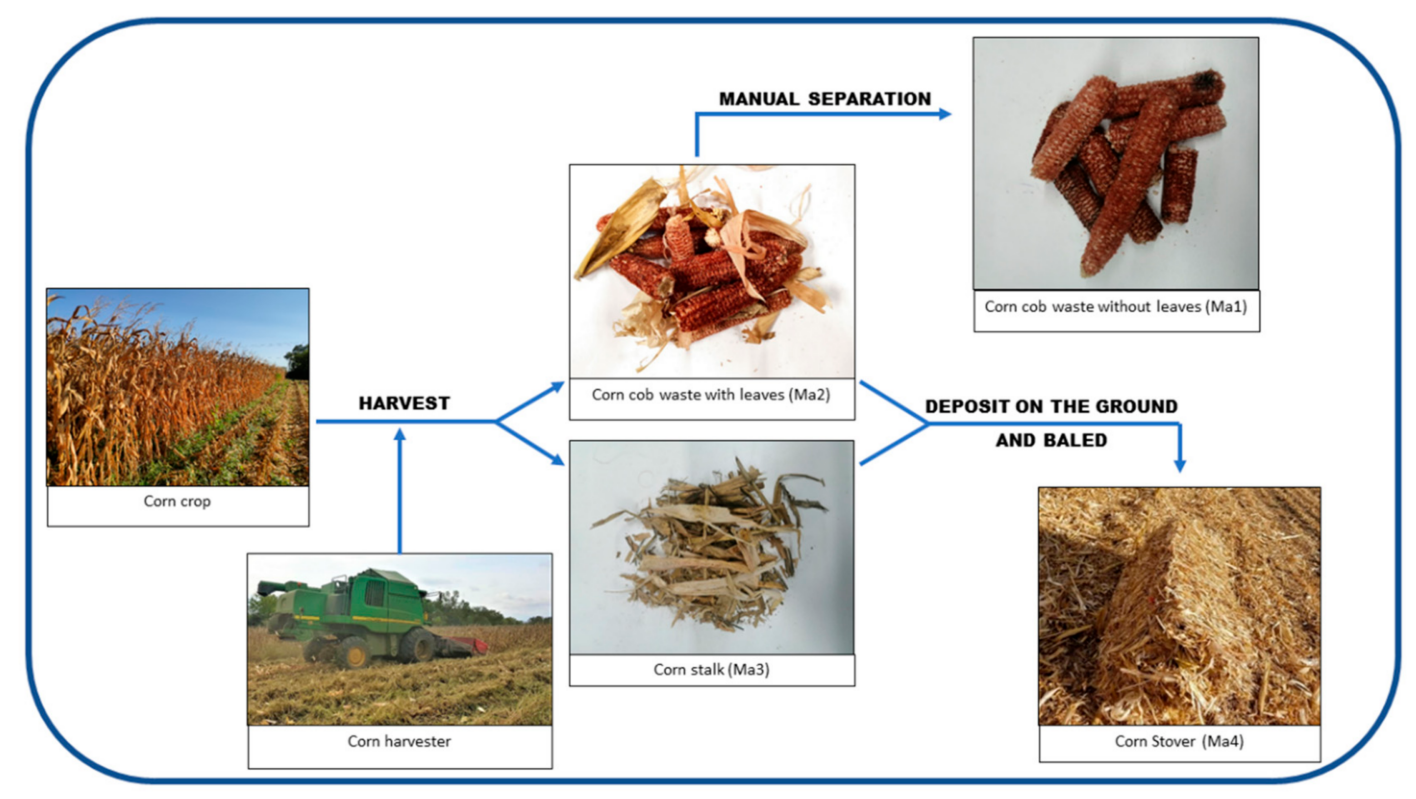

Figure 1. Scheme of harvest system and residues from corn crops.

Thus, four residues will be studied in this work. The first one is the corncob waste without leaves (Ma1), where the waste was collected without any contact with the soil and corn leaves were removed manually. The second one is corncob waste with the leaves that wrap the corncob (Ma2). The third one is corn stalk with its leaves, immediately collected from the harvester without any contact with soil (Ma3). The fourth residue is the corn stover, generated by the harvester and collected on the soil, including corncob waste, stalk and leaves (Ma4) (remaining several days on the soil), which, depending on the weather conditions, can vary from 3 to 10 days until optimal humidity is achieved for subsequent baling.

\subsubsection{Sample Preparation}

The samples were ground in a hammer mill (CIP Line SG40, Italy), using a $5 \mathrm{~mm}$ sieve at the exit of the machine. Afterwards, in order to obtain an optimum granulometry, the samples were ground in a ball mill (Retsch MM 301, Germany).

\subsection{Proximate and Ultimate Analysis}

Moisture was calculated according to the standard [20], by using a balance (precision $\pm 0.0001 \mathrm{~g}$ ) and a stove (at $105^{\circ} \mathrm{C}$ ). In order to determine bulk density, a test was carried out following the standard [21]. For ultimate and proximate analyses, an analyzer (Eurovector EA 3000, Italy) was used, according to the standards [22,23]. Volatile compound percentage was determined by using an oven at $900{ }^{\circ} \mathrm{C}$, according to the standard [24], whereas ash content was obtained by using an oven at $550{ }^{\circ} \mathrm{C}$ [25]. Based on volatile matter and ash percentages, fixed carbon percentage was determined by subtraction of $100 \%$.

\subsection{Higher Heating Value}

For higher heating value (HHV) analysis of the samples, a calorimetric pump (ParrCalorímetro 6400, US) was used, with a temperature resolution of $0.0001^{\circ} \mathrm{C}$ and an oxygen pressure of $450 \mathrm{psig}$, according to the standard [26].

For HHV assessment, the correction related to the heat released during sulfuric acid generation, due to sulfur content in different wastes, was taken into account.

\subsection{Ash Composition}

Ash composition analysis of the different residues was carried out in the Solids and Surface Analysis and Characterization Laboratory, belonging to the Support and Research 
Services of the University of Extremadura. The method used was the X-ray excitation (with $\mathrm{Rh}$ as anode material) at $4 \mathrm{~kW}$.

\subsection{TG Analysis}

The thermogravimetric analysis (TG) was carried out by using a thermobalance (NETZSCH STA 449F5 Jupiter, Germany), located in the Cork, Wood and Charcoal Institute belonging to CICYTEX. Different samples from each residue were selected, with variable weights from 30 to $38 \mathrm{mg}$ in an aluminum crucible $\left(\mathrm{Al}_{2} \mathrm{O}_{3}\right)$, undergoing temperatures between 30 to $900{ }^{\circ} \mathrm{C}$ with a temperature ramp of $20{ }^{\circ} \mathrm{C} / \mathrm{min}$ in argon atmosphere, and a gas flow of $50 \mathrm{~mL} / \mathrm{min}$, and an air atmosphere $(80 / 20)$ with a gas flow of $50 \mathrm{~mL} / \mathrm{min}$. The protective gas was argon $(20 \mathrm{~mL} / \mathrm{min})$. To conduct properly the thermogravimetric analysis the Difference Thermogravimetry curve (DTG) has been calculated, corresponding to the first derivative of the DT curve. All the samples were done in triplicate in order to assure a suitable reproducibility of results.

In order to determine the different temperature events during pyrolysis, under inert atmosphere (argon), and combustion, under air atmosphere, the tangent method [7,27,28], has been selected, which is shown in Figure 2.

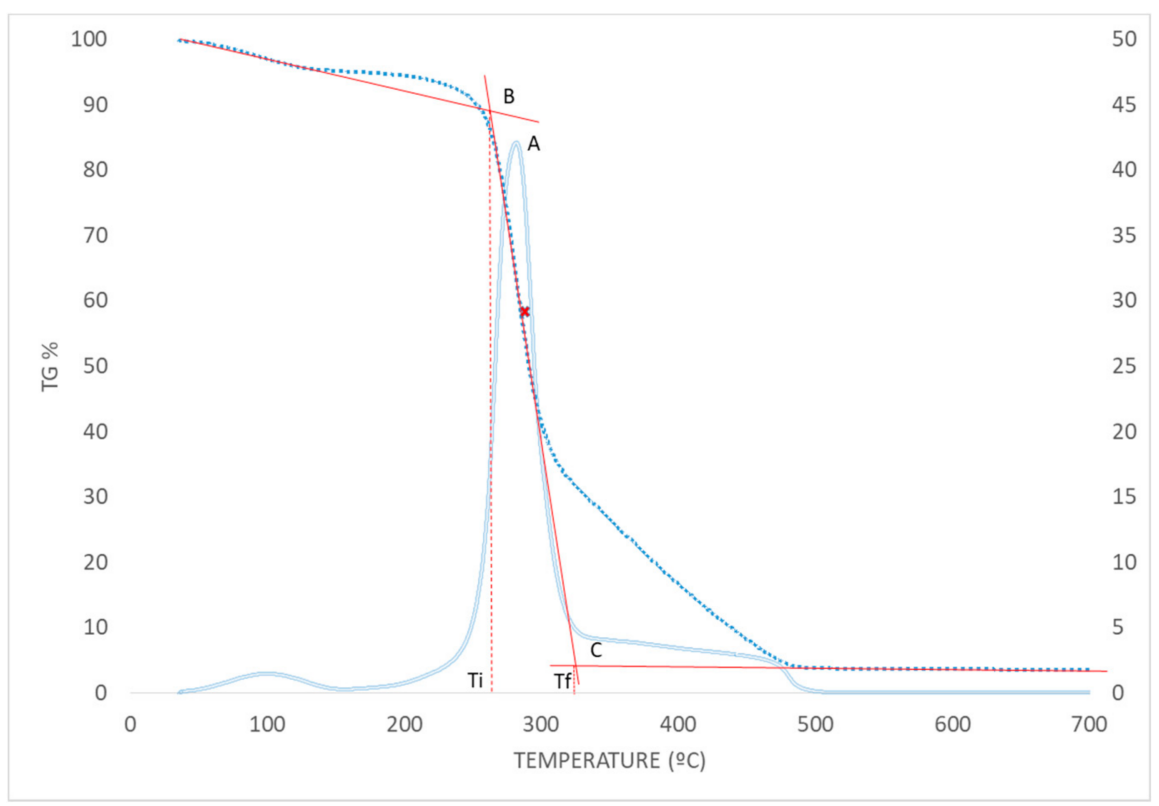

Figure 2. Tangent method.

Concerning combustion, the temperature at which combustion or burning ended was considered when the residual mass was $1 \%$ of the original mass [28-30].

In the case of pyrolysis, the main characteristic temperatures of the process were determined, such as the starting temperature of fast pyrolysis $T_{m}$ (corresponding to the starting temperature of the thermal process according to the tangent method), the end temperature of pyrolysis, $T_{f}$ (corresponding to the end temperature of the thermal process according to the tangent method), and the peak temperature $T_{p}$ (the temperature at which the maximum weight loss rate took place). Moreover, the pyrolysis index, $P_{i}$, was calculated, which is defined as the easiness to start the process, and the end of pyrolysis index, $P_{f}$, which is useful to assess the yield of pyrolysis in biomass, was also obtained [31]:

$$
\begin{gathered}
P_{i}=\frac{D T G_{\max }}{t_{p} t_{m}} \\
P_{f}=\frac{D T G_{\max }}{\Delta t_{1 / 2} t_{p} t_{f}}
\end{gathered}
$$


where $D T G_{\max }(\% / \mathrm{min})$ denotes the maximum pyrolysis rate; $t_{p}(\mathrm{~min})$ is the corresponding time of the maximum pyrolysis rate; $\Delta t_{1 / 2}(\mathrm{~min})$ represents the time range that corresponds to $D T G / D T G_{\max }=\frac{1}{2}$; and $t_{m}(\mathrm{~min})$ and $t_{f}(\mathrm{~min})$ is the time associated with $T_{m}$ and $T_{f}$, respectively.

The pyrolysis characteristic index $P$ was calculated, which shows the energy required to pyrolyze a fuel [31]:

$$
P=\frac{D T G_{\max } D T G_{m e a n}}{T_{m}^{2} T_{f}}
$$

where $D T G_{\text {mean }}(\% / \mathrm{min})$ represents the mean pyrolysis rate.

Regarding combustion, the ignition temperature, $T_{i}$ (corresponding to the starting temperature of the thermal process according to the tangent method), the burnout temperature, $T_{f}$, and peak temperature, $T_{p}$, (the temperature at which the maximum weight loss rate was observed) were determined. Moreover, the ignition index, $D_{i}$, and the burnout index, $D_{f}$, were calculated to describe the ignition and burnout characteristics of the residues [29]:

$$
\begin{aligned}
D_{i} & =\frac{D T G_{\max }}{t_{p} t_{i}} \\
D_{f} & =\frac{D T G_{\max }}{\Delta t_{1 / 2} t_{p} t_{f}}
\end{aligned}
$$

where $D T G_{\max }(\% / \mathrm{min})$ denotes the maximum combustion rate; $t_{p}(\mathrm{~min})$ is the corresponding time of the maximum combustion rate; $\Delta t_{1 / 2}(\mathrm{~min})$ represents the time range that corresponds to $D T G / D T G_{\max }=\frac{1}{2}$; and $t_{i}(\mathrm{~min})$ and $t_{f}(\mathrm{~min})$ represent the ignition time and burnout time, respectively.

The devolatilization index $D$ and the combustion characteristic index $S$ were calculated. $D$ index is related to the volatile compounds evolved during combustion [32], whereas $S$ index shows the ignition, combustion and burning properties of a fuel [28,33]:

$$
\begin{gathered}
D=\frac{D T G_{\max }}{T_{p} \Delta T} \\
S=\frac{D T G_{\text {max }} D T G_{\text {mean }}}{T_{i}^{2} T_{f}}
\end{gathered}
$$

where $D T G_{\text {mean }}(\% / \mathrm{min})$ represents the mean combustion rate and $\Delta t$ is the difference between $T_{p}$ and $T_{i}$.

\section{Results and Discussion}

\begin{tabular}{|c|c|c|c|c|c|c|c|c|c|c|c|}
\hline & \multirow{2}{*}{$\begin{array}{l}\text { Moisture } \\
\% \text { wb }\end{array}$} & \multirow{2}{*}{$\begin{array}{c}\text { Density } \\
\mathrm{kg} / \mathrm{m}^{3} \text { wb }\end{array}$} & \multicolumn{5}{|c|}{ Ultimate Analysis (\% db) } & \multicolumn{3}{|c|}{ Proximate Analysis (\% db) } & \multirow[t]{2}{*}{$\begin{array}{c}\text { HHV } \\
\text { MJ/kg db }\end{array}$} \\
\hline & & & $\mathrm{C}$ & $\mathbf{H}$ & $\mathbf{N}$ & $\mathbf{S}$ & $\mathbf{O}$ & Ash & $\begin{array}{l}\text { Volatile } \\
\text { Matter }\end{array}$ & $\begin{array}{l}\text { Fixed } \\
\text { Carbon }\end{array}$ & \\
\hline Ma 1 & 11.30 & 220.02 & 41.57 & 6.48 & 0.35 & 0.04 & 51.56 & 1.92 & 85.79 & 12.29 & 16.54 \\
\hline Ma 2 & 10.37 & 204.80 & 42.20 & 6.35 & 0.34 & 0.04 & 51.07 & 1.98 & 86.72 & 11.30 & 16.72 \\
\hline Ma 3 & 9.23 & 121.80 & 41.44 & 6.37 & 0.54 & 0.07 & 51.58 & 4.41 & 80.72 & 14.87 & 16.52 \\
\hline Ma 4 & 7.15 & 96.86 & 39.98 & 5.87 & 0.50 & 0.08 & 53.57 & 9.68 & 79.75 & 10.57 & 16.37 \\
\hline
\end{tabular}

\subsection{Proximate and Ultimate Analysis and Higher Heating Value}

The results concerning the proximate and ultimate analyses, as well as the moisture, density and heating value, are shown in Table 1.

Table 1. Proximate and ultimate analyses (db: dry basis, wb: wet basis).

Concerning the moisture obtained, there was a variation (depending on the kind of waste) from 7.15 to $11.30 \%$, but less than $15 \%$, which is the recommended value for 
subsequent pelletizing, according to the standard [19]; it did not need any previous drying process.

Regarding density, there were clear differences among the four residues, due to their different natures, and therefore the densification ratios will be very different. Zhang et al. [34] obtained densities of $282.38 \mathrm{~kg} / \mathrm{m}^{3}$ (for corncob waste) and $127.32 \mathrm{~kg} / \mathrm{m}^{3}$ (for stalk); these values were very similar to those obtained in this work.

With regard to the ultimate analysis, it is interesting to focus on $\mathrm{N}$ and $\mathrm{S}$ content, due to the possible $\mathrm{NOx}$ and $\mathrm{SO}_{2}$ emissions. For nitrogen, the values ranged from $0.35 \%$ to $0.5 \%$, whereas in the case of sulfur, the range was from 0.039 to $0.080 \%$. In both cases, the values were higher in the wastes that contained corn stalk. Nevertheless, the results were below the upper limit established by the standard [19].

Regarding the proximate analysis, in the case of volatile matter, the residues containing corncob waste had a higher value, whereas for corn stover this content was lower (79.75\%). Other authors like Rony et al. [35] obtained a volatile matter of $81.1 \%$ for corn stover, very similar to the result obtained in the present study.

Regarding ash content, lower values were observed for the residues containing corncob waste than for those containing corn stalk. Moreover, the influence of leaves on the corncob waste was not significant when it came to ash content. In the case of Ma1, Ma2 and Ma3, ash content was $1.92 \%, 1.98 \%$ and $4.41 \%$, respectively; compared to other biofuels, it can be observed that other herbaceous biomass, such as rice husk or wheat straw, had ash contents of $18.91 \%$ [15] and $9.28 \%$ [36], respectively, whereas in woody biomass, such as the biomass from eucalyptus or stone pine, the ash content was $7.21 \%$ and $3.03 \%$ [28], respectively. Therefore, the ash content of the analyzed samples had suitable values for thermal use. Taking into account the standard required to use these wastes as biomass, class A pellets would be obtained from Ma1, Ma2 and Ma3 residues [19]. On the other hand, ash content considerably increased for Ma4, which remained on the soil and was degraded over time, and directly baled on the ground (implying higher amounts of impurities). These high ash values showed that this kind of waste would not be a suitable material for its thermal use in densification. If the results related to corn stover are compared with other studies, Gai et al. [15] obtained ash content values of $11.80 \%$ for corn stover, whereas Kumar et al. [16] obtained a value of $8.18 \%$. In both cases, these results were similar and as high as the obtained ones in Ma4, the corn stover studied in this work.

Regarding heating value, the results observed were similar to those included in other studies about corn wastes [35]. Taking into account the standards for solid biofuels, the heating value obtained would be suitable for pellet production (A class) [19].

\subsection{Ash Composition}

In Table 2, the results obtained for ash composition are included. In general, the compounds obtained are common in agricultural biomass, according to studies carried out by Vassilev et al. [37,38].

Table 2. Ash composition after combustion.

\begin{tabular}{ccccccccccccccccc}
\hline \multicolumn{110}{c}{ Ash Composition (\% db) } \\
\hline & $\mathbf{K}$ & $\mathbf{C l}$ & $\mathbf{S i}$ & $\mathbf{P}$ & $\mathbf{M g}$ & $\mathbf{C a}$ & $\mathbf{S}$ & $\mathbf{K}_{\mathbf{2}} \mathbf{O}$ & $\mathbf{S i O}_{\mathbf{2}}$ & $\mathbf{P}_{\mathbf{2}} \mathbf{O}_{\mathbf{5}}$ & $\mathbf{C a O}$ & $\mathbf{M g O}$ & $\mathbf{S O}_{\mathbf{3}}$ & $\mathbf{A l}_{\mathbf{2}} \mathbf{O}_{\mathbf{3}}$ & $\mathbf{F e}_{\mathbf{2}} \mathbf{O}_{\mathbf{3}}$ & $\mathbf{Z n O}$ \\
\hline Ma 1 & 48.20 & 9.53 & 6.27 & 3.59 & 2.48 & 1.73 & 1.23 & 58.11 & 13.40 & 8.23 & 2.42 & 4.12 & 3.08 & 0.12 & 0.32 & 0.24 \\
Ma 2 & 46.45 & 9.65 & 7.94 & 2.83 & 2.35 & 2.13 & 1.12 & 55.96 & 17.00 & 6.48 & 2.98 & 3.90 & 2.80 & 0.20 & 0.40 & 0.13 \\
Ma 3 & 29.07 & 7.33 & 13.42 & 2.67 & 4.87 & 6.68 & 1.26 & 35.02 & 28.72 & 6.12 & 9.35 & 8.07 & 3.14 & 0.78 & 0.59 & 0.07 \\
Ma 4 & 18.93 & 5.98 & 17.57 & 1.55 & 7.05 & 8.04 & 1.24 & 23.40 & 37.58 & 3.56 & 11.26 & 11.70 & 3.09 & 1.51 & 1.06 & 0.05 \\
\hline
\end{tabular}

In the ash analysis of biofuels, it is important to analyze $\mathrm{K}_{2} \mathrm{O}$ and $\mathrm{SiO}_{2}$ content. Arranz et al. [10] pointed out that both compounds affected the melting point of ash, and the subsequent possibility to produce blockages in combustion systems. In addition, Rodríguez et al. [39] concluded that high $\mathrm{SiO}_{2}$ concentrations could increase the risk of 
slagging. Regarding $\mathrm{K}_{2} \mathrm{O}$ content, its value ranged from $23.4 \%$ to $58.11 \%$, being higher in residues with corncob waste, whereas $\mathrm{SiO}_{2}$ ranged from $13.4 \%$ to $37.58 \%$, being higher for wastes containing corn stalk, especially in the case of corn stover where there might be a considerable number of impurities from the soil.

When considering pelletizing of these wastes, the content in these compounds should be taken into account, as it could adversely affect combustion systems, due to slag generation and other elements generated, possibly because of ash melting.

\subsection{Thermal Behavior}

\subsubsection{Pyrolysis}

The characteristics inferred from the thermal analysis during pyrolysis are useful to determine the capacity of maintaining self-energy balance in corn residues. The pyrolysis profiles of the wastes can be seen in Figure 3, where the weight loss with temperature and over time can be observed. In Table 3, the main pyrolysis parameters for the different samples are shown.

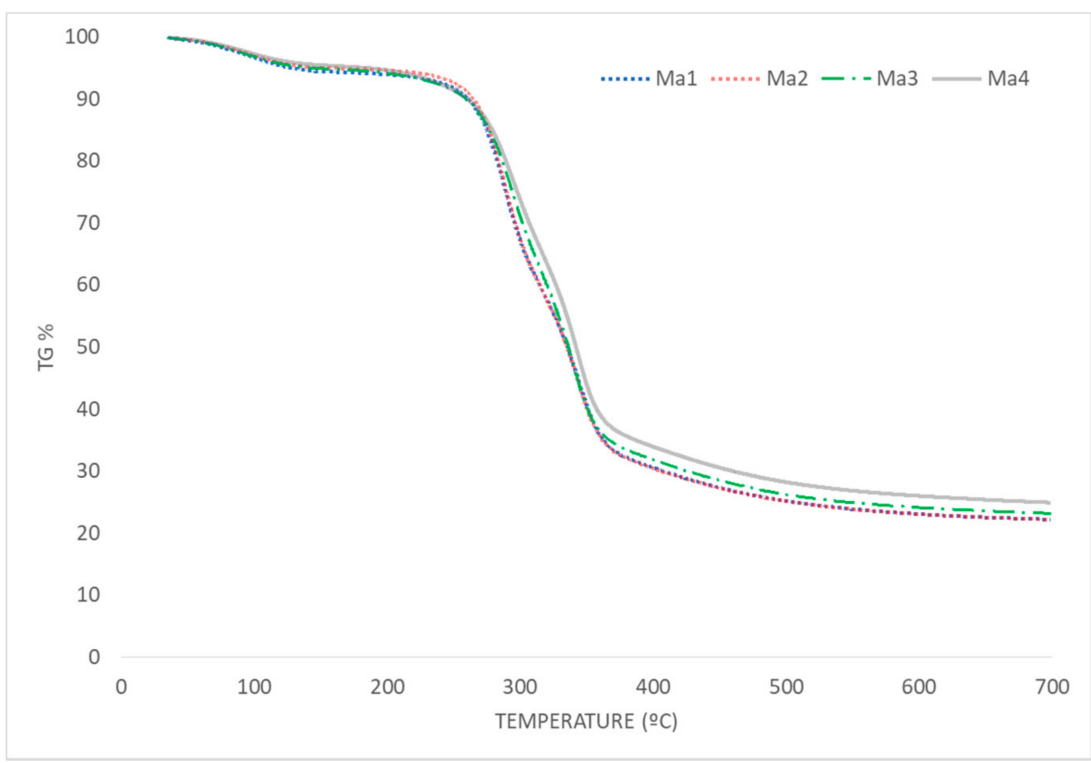

(a)

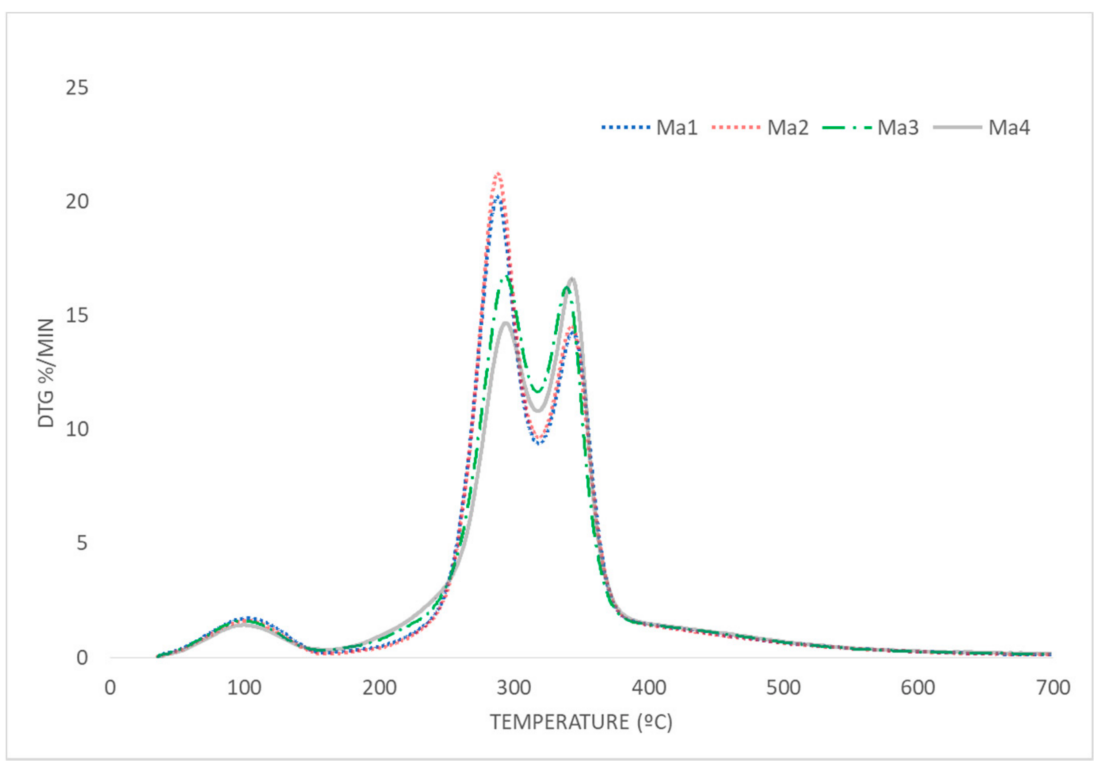

(b)

Figure 3. (a) Thermogravimetric (TG) pyrolysis and (b) DTG Pyrolysis. 
Table 3. Main pyrolysis parameters (inert atmosphere).

\begin{tabular}{ccccc}
\hline & Main Pyrolysis Parameters & & \\
\hline & Ma1 & Ma2 & Ma3 & Ma4 \\
\hline Fast Pyrolysis initial $T_{m}\left({ }^{\circ} \mathrm{C}\right)$ & 272.5 & 272.3 & 269.9 & 284.6 \\
Peak temperature $T_{p}\left({ }^{\circ} \mathrm{C}\right)$ & 287.6 & 287.8 & 293.2 & 342.9 \\
Shoulder peak $T_{s}\left({ }^{\circ} \mathrm{C}\right)$ & 343.5 & 342.4 & 339.0 & 293.7 \\
Pyrolysis finish $T_{f}\left({ }^{\circ} \mathrm{C}\right)$ & 374.5 & 373.6 & 368.9 & 371.3 \\
DTG peak max $(\% / \mathrm{min})$ & 20.23 & 21.24 & 16.76 & 16.62 \\
DTG shoulder $(\% / \mathrm{min})$ & 14.25 & 14.53 & 16.26 & 14.68 \\
DTG mean $(\% / \mathrm{min})$ & 2.08 & 2.09 & 2.05 & 2.00 \\
Fast Pyrolysis initial time $t_{m}(\mathrm{~min})$ & 12.40 & 12.39 & 12.31 & 12.88 \\
Peak time $t_{p}(\mathrm{~min})$ & 12.97 & 12.98 & 13.21 & 15.42 \\
Pyrolysis finish time $t_{f}(\mathrm{~min})$ & 16.97 & 16.93 & 16.69 & 16.81 \\
$\Delta t_{1 / 2}(\mathrm{~min})$ & 0.72 & 0.68 & 0.89 & 2.95 \\
$P_{i}\left(\% /\right.$ min $\left.^{3} \times 10^{-3}\right)$ & 125.79 & 132.07 & 103.07 & 83.68 \\
$P_{f}\left(\% /\right.$ min $\left.^{4} \times 10^{-3}\right)$ & 127.66 & 142.14 & 85.41 & 21.73 \\
$P\left(\% /{ }^{\circ} \mathrm{C}^{3} \times 10^{-3}\right)$ & 16.13 & 17.08 & 13.58 & 11.92 \\
Residual Mass $(\%)$ & 21.30 & 21.34 & 22.22 & 23.96 \\
\hline
\end{tabular}

In the representative pyrolysis curves of the four residues, shown in Figure 3, a similar shape was observed for all the cases, with a decrease in weight over temperature, due to moisture loss and the volatilization of compounds in the samples.

The thermal degradation, taking place in three stages, can be seen in Figure 3. The first stage is due to moisture removal and the beginning of hemicellulose decomposition [11], up to the beginning of fast pyrolysis $T_{m}$, which ranges from 269.99 to $284.6{ }^{\circ} \mathrm{C}$ in the different samples. The lower this temperature is, the better the characteristics of the waste for pyrolysis are, obtaining lower temperatures for Ma1, Ma2 and Ma3 wastes whereas the Ma4 sample had the highest $T_{m}$, which could be due to the contact of this waste with the ground causing higher amounts of impurities.

During the second stage, the main pyrolysis process took place, from the beginning of fast pyrolysis $T_{m}$ to the end temperature of pyrolysis $T_{f}$, as shown in Table 3 . In this second stage, a sharp increase in the weight loss rate took place with further thermal degradation, observing two peaks related to hemicellulose and cellulose decomposition, whereas lignin decomposed during the second and third stage without any characteristic peaks [40]. Aboyade et al. [12] described the first peak as corresponding to hemicellulose decomposition (usually ranging from 160 to $360^{\circ} \mathrm{C}$ ), whereas the second peak corresponded to cellulose decomposition (between 240 to $390{ }^{\circ} \mathrm{C}$ ). Temperature peaks where the maximum weight loss took place were lower in Ma1 and Ma2 (287.6 and $287.8^{\circ} \mathrm{C}$, respectively), and this fact means that they presented greater ease in thermal degradation during the pyrolysis process. The temperature peaks were higher for Ma3 and Ma4, with values of 293.2 and $342.9^{\circ} \mathrm{C}$, respectively, which implies that Ma4 had worse characteristics for pyrolysis. Compared to other similar wastes, such as rice husk, Gai et al. [15] obtained a value for a temperature peak of $325^{\circ} \mathrm{C}$, observing better characteristics in corn wastes that were not in contact with the soil, that is, the Ma1, Ma2 and Ma3 samples. In other kinds of biomass, such as woody biomass, higher peak temperatures were observed, as in the case of poplar with peak temperatures at around $345^{\circ} \mathrm{C}$ [31]. Regarding the end temperature for pyrolysis, very similar values were observed; they were slightly lower for Ma3 and Ma4 samples (368.9 and $371.3^{\circ} \mathrm{C}$, respectively), than for Ma1 and Ma2 $\left(374.5\right.$ and $373.6^{\circ} \mathrm{C}$ ), respectively.

Finally, in the third stage (carbonization), a slow decomposition of the wastes took place, generating ash and fixed carbon as final products. The residual mass of the four samples at the end of the tests (at around $900{ }^{\circ} \mathrm{C}$ ), are shown in Table 3. This residual mass included ash content and fixed carbon [8], obtaining lower values for Ma1 and Ma2 ( 21.30 and $21.34 \%$, respectively) and a higher value for Ma4 (23.96\%). These results are in accordance with the ash content and fixed carbon values included in Table 1. 
Better characteristics can be observed for the residues mainly composed of corncob waste for pyrolysis [8], Ma1 and Ma2, due to the higher content in volatile compounds on a dry basis (Table 1) and the lower content in wastes (Table 3), whereas Ma4 waste has the worst characteristics as it is degraded in contact with the ground. Nevertheless, comparing similar wastes studied in other works, as in the case of rice husk with a residual mass of $36.92 \%$ [15], the good behavior of these wastes for this thermal process can be concluded.

In Table 3, main pyrolysis indexes are shown. Concerning $P_{i}$, the higher this value was, the easier it was for pyrolysis to take place in the waste, obtaining higher values for Ma1 and Ma2, 125.79 and $132.07 \% / \mathrm{min}^{3} \times 10^{-3}$ respectively, than in the case of Ma3 and Ma4, 103.07 and $83.08 \% / \mathrm{min}^{3} \times 10^{-3}$ respectively. Regarding the $P$ index, higher values were observed for Ma1 and Ma2, 16.13 and $17.08 \% /{ }^{\circ} \mathrm{C}^{3} \times 10^{-3}$, respectively, with a value of 13.58 and $11.92 \% /{ }^{\circ} \mathrm{C}^{3} \times 10^{-3}$ for Ma3 and Ma4, respectively. This fact implies that the residues with a higher proportion of corncob waste had a lower peak temperature and, therefore, the pyrolysis process started earlier [31].

With regard to the $P_{f}$ index, higher values were observed in Ma1 $\left(127.66 \% / \mathrm{min}^{4} \times 10^{-3}\right)$ and Ma2 $\left(142.14 \% / \mathrm{min}^{4} \times 10^{-3}\right)$ residues; this was due to the higher values of the peak max in the DTG curve and the lower values of time when the temperature peaks were reached. As in the case of the previous indexes, it can be concluded that these wastes are more suitable for energy use.

Comparing the values of the $P_{i}, P$ and $P_{f}$ index, it can be said that Ma1 and Ma2 residues, mainly composed of corncob waste, are better than Ma3 and Ma4 (which mainly contain corn stalk) for pyrolysis processes. Regarding the residues with corncob waste, Ma1 and Ma2, the separation of leaves makes no sense as, even though there is an increase in ash content, its separation would worsen the properties for pyrolysis. Moreover, and observing the values obtained, the negative effect of the long permanence of the waste on the soil (as in the case of Ma4) was clearly proved.

In Figure 4, a comparison of the pyrolysis indexes is shown, indicating the relative percentage with respect to the highest value obtained for each index. In the graph shown, the residue with the best pyrolysis performance appears on the outside, whereas the residue with the worst characteristics appears in the innermost part of the geometric figure. As can be seen, the most favorable residue is Ma2, whereas the one with the worst behavior is Ma4.

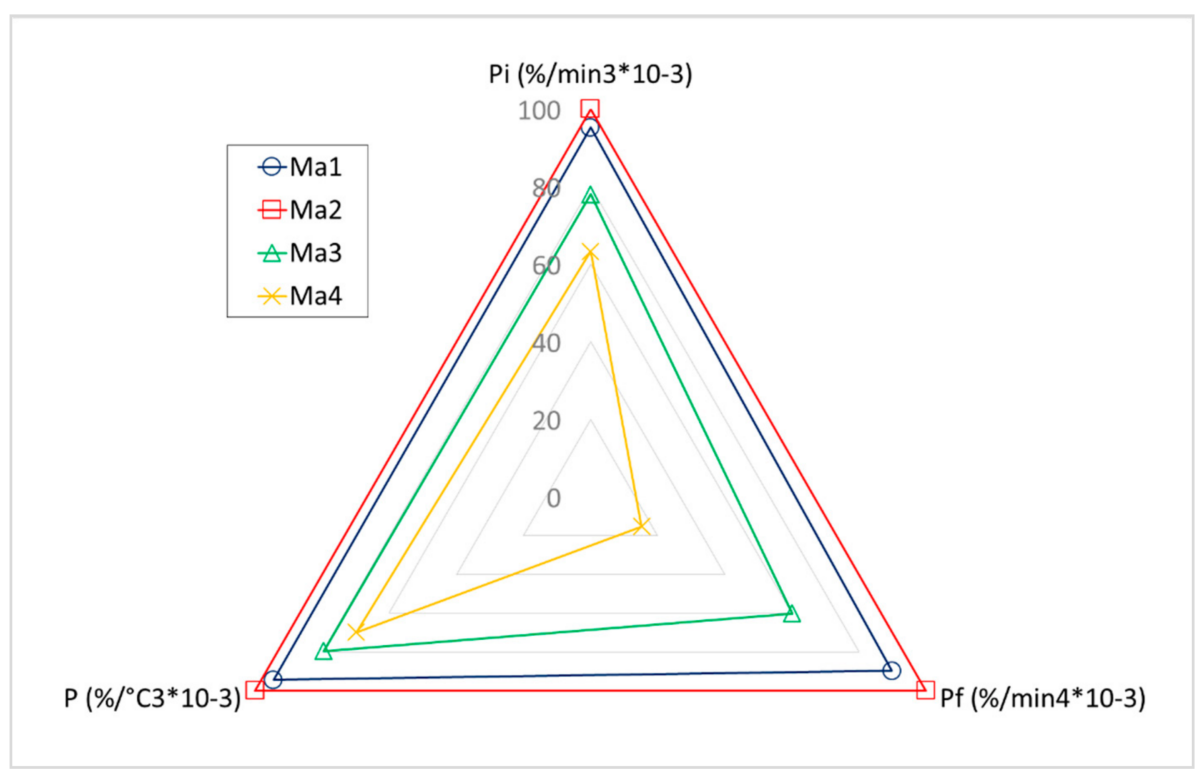

Figure 4. Pyrolysis indexes.

To sum up, with regard to the pyrolysis process, optimum characteristics were observed for corncob waste or samples with the majority of its content containing this residue (Ma1 and Ma2), without any significant difference in the presence of leaves. In this case, 
the selective collection of residues is highly recommended. Moreover, the direct collection by harvesting machines (without any contact between residues and soil) is advisable, as the subsequent degradation produced unfavorable results in pyrolysis.

\subsubsection{Combustion}

The characteristics obtained from the thermal analysis were used to compare the reactivity and combustibility of corn residues. The combustion profiles of the wastes can be seen in Figure 5, where the weight loss due to the increase in temperature can be observed. The main combustion parameters for the different samples are included in Table 4.

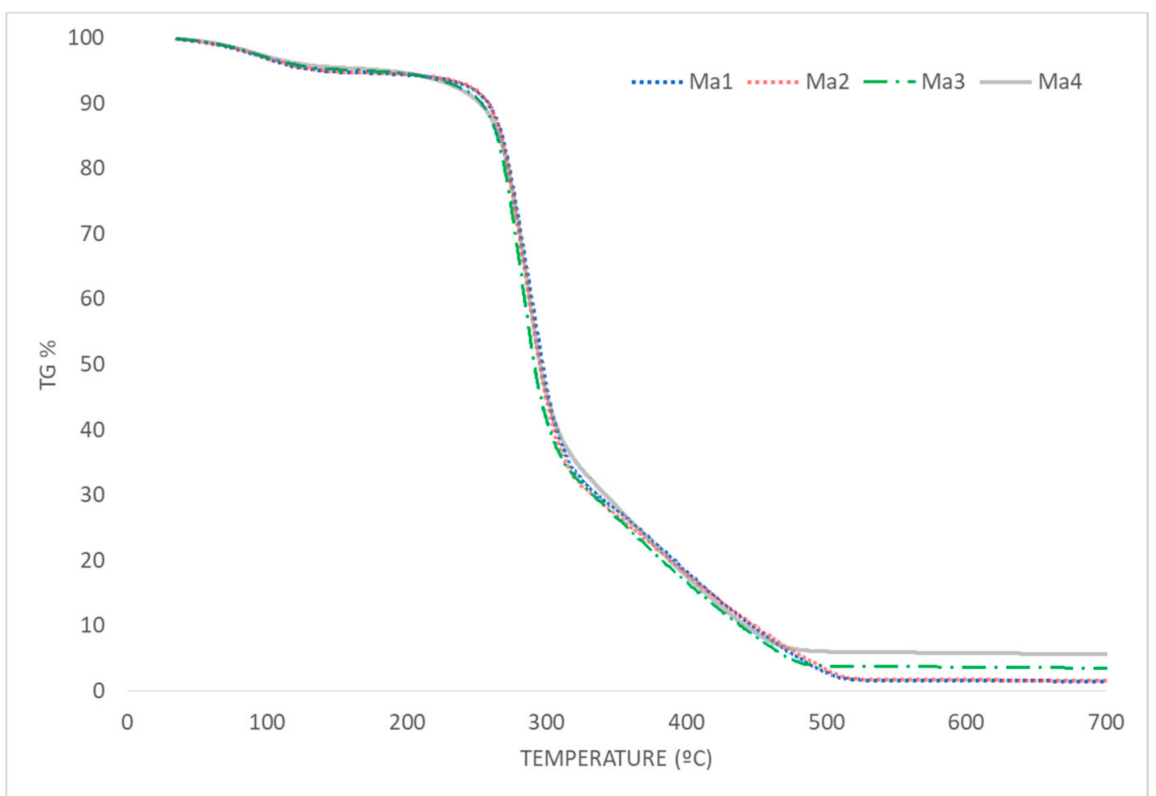

(a)

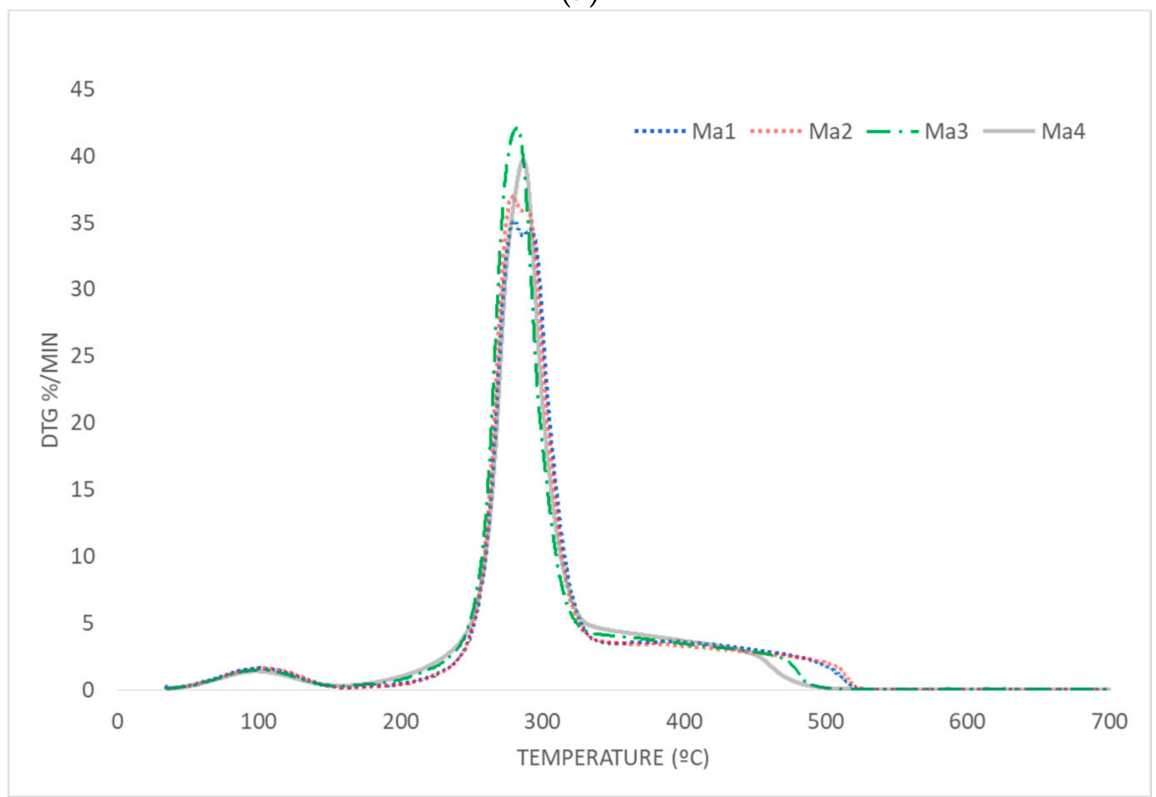

(b)

Figure 5. (a) TG combustion and (b) DTG combustion. 
Table 4. Main combustion parameters (air atmosphere).

\begin{tabular}{ccccc}
\hline & Main Combustion Parameters & & \\
\hline & Ma1 & Ma2 & Ma3 & Ma4 \\
\hline T for $5 \%$ weigh loss $\left({ }^{\circ} \mathrm{C}\right)$ & 135.0 & 137.2 & 164.5 & 183.1 \\
Ignition temperature $T_{i}\left({ }^{\circ} \mathrm{C}\right)$ & 266.6 & 266.0 & 264.6 & 266.6 \\
Peak temperature $T_{p}\left({ }^{\circ} \mathrm{C}\right)$ & 279.6 & 278.6 & 281.5 & 286.3 \\
Burnout temperature $T_{f}\left({ }^{\circ} \mathrm{C}\right)$ & 506.8 & 511.4 & 485.8 & 486.6 \\
DTG max $(\% / \min )$ & 35.12 & 36.99 & 42.10 & 39.72 \\
DTG mean $(\% / \min )$ & 2.73 & 2.74 & 2.74 & 2.66 \\
Ignition time $t_{i}(\min )$ & 12.18 & 12.15 & 12.10 & 12.18 \\
Peak time $t_{p}(\min )$ & 12.64 & 12.59 & 12.69 & 12.89 \\
Burnout time $t_{f}(\mathrm{~min})$ & 23.96 & 24.12 & 22.9 & 23.00 \\
$\Delta t_{1 / 2}(\min )$ & 14.0 & 13.8 & 17.0 & 18.6 \\
$D_{i}\left(\% / \min ^{3} \times 10^{-3}\right)$ & 228.12 & 241.81 & 274.18 & 252.99 \\
$S\left(\% /{ }^{\circ} \mathrm{C}^{3} \times 10^{-7}\right)$ & 26.62 & 28.01 & 33.92 & 30.55 \\
$D\left(\% /{ }^{\circ} \mathrm{C}^{2} \times 10^{-3}\right)$ & 9.66 & 10.54 & 8.85 & 7.04 \\
$D_{f}\left(\% / \min ^{4} \times 10^{-3}\right)$ & 231.93 & 248.59 & 241.45 & 199.96 \\
Residual mass $(\%)$ & 1.22 & 1.24 & 3.10 & 5.23 \\
\hline
\end{tabular}

According to the results obtained from TG tests, and those inferred from Figure 5, three different areas or stages were observed during combustion of these residues. The first stage was related to moisture loss, from room temperature to the temperature at which $5 \%$ weight loss took place [41], ranging between $135.0^{\circ} \mathrm{C}$ for Ma1 and $183.1^{\circ} \mathrm{C}$ for Ma4, according to Table 4 . At higher temperatures, a faster stage started with the combustion of volatile compounds, observing a temperature peak between 278.6 and $286.3^{\circ} \mathrm{C}$, depending on the sample (see Table 4), due to the thermal decomposition of cellulose and hemicellulose, up to the final temperature of this stage, where a change in the slope of the TG curve took place, ranging from 320.6 to $335.5^{\circ} \mathrm{C}$, depending on the sample. The third stage corresponded to lignin decomposition and char combustion, finishing at the burning temperature, ranging from 485.8 to $511.4{ }^{\circ} \mathrm{C}$. Lastly, a final stage took place up to $900{ }^{\circ} \mathrm{C}$, the temperature at which the test finished.

With regard to the ignition temperature and taking into account that it is the temperature at which the sample starts burning, the lower this value is, the better combustibility values the waste will have, obtaining similar values for the four samples, varying from $264.6^{\circ} \mathrm{C}$ for Ma3 to $266.6^{\circ} \mathrm{C}$ for Ma1 and Ma4 wastes. Comparing this value with other kinds of biomass such as woody eucalyptus biomass (with an ignition temperature of $295.5^{\circ} \mathrm{C}$ ) [28], it can be considered that the combustibility conditions are suitable, obtaining values that are very similar to other herbaceous wastes such as wheat straw $\left(262^{\circ} \mathrm{C}\right)$ [36] or tobacco stem $\left(250^{\circ} \mathrm{C}\right)$ [41]. This is due to the fact that herbaceous wastes, as in the case of corn, cellulose and hemicellulose content, are higher than in the case of woody biomass (richer in lignin), and consequently a lower temperature for volatilization is required.

In Table 4 the values of the combustion indexes are shown. With regard to the $D_{i}$ index, the higher it is, the easier it is for combustion to take place, obtaining higher values for Ma3 and Ma4 (274.18 and $252.99 \% / \mathrm{min}^{3} \times 10^{-3}$, respectively), than in the case of Ma1 and Ma2 samples (with values of 228.12 and $241.81 \% / \mathrm{min}^{3} \times 10^{-3}$, respectively). In addition, comparing Ma1 and Ma2 samples, a better value of this index was observed for the latter, which means that the leaves included in corncob waste facilitate combustion.

The $S$ index is useful to determine the ignition behavior. The larger the value of the $S$ index, the higher the combustion activity. As in the case of $D_{i}$, higher values were observed for M3 and M4 samples $\left(33.92 \% /{ }^{\circ} \mathrm{C}^{3} \times 10^{-7}\right.$ and $30.55 \% /{ }^{\circ} \mathrm{C}^{3} \times 10^{-7}$ respectively), than for Ma1 and Ma2 $\left(26.62 \% /{ }^{\circ} \mathrm{C}^{3} \times 10^{-7}\right.$ and $28.01 \% /{ }^{\circ} \mathrm{C}^{3} \times 10^{-7}$, respectively). Furthermore, comparing Ma1 and Ma2 samples, a better value for this index was observed for Ma2, so it can be concluded that the leaves mixed with the corncob waste improved the activity during combustion. Parshetti et al. [42] consider good general combustion performance 
when this value exceeds $2 \% /{ }^{\circ} \mathrm{C}^{3} \times 10^{-7}$, which is amply surpassed by all the wastes studied in this work.

Regarding the $D$ index, it is related to the release of volatile compounds, and its value increases with the increase in the maximum weight loss rate and the decrease in temperature at which these volatile compounds are evolved. Contrary to the $D_{i}$ index, this value was lower for Ma3 and Ma4 samples (8.85 and $7.04 \% /{ }^{\circ} \mathrm{C}^{2} \times 10^{-3}$ respectively), followed by Ma1 with a value of $9.66 \% /{ }^{\circ} \mathrm{C}^{2} \times 10^{-3}$; the optimum value was obtained for the Ma2 sample, with an index of $10.54 \% /{ }^{\circ} \mathrm{C}^{2} \times 10^{-3}$. Thus, the release of volatile compounds was favored in samples of corncob waste with leaves.

Regarding the $D_{f}$ index, the lowest value was obtained for Ma4 waste, at $199.96 \% / \mathrm{min}^{4}$ $\times 10^{-3}$. This value decreased when $\Delta t_{2}$ increased, and in this case this parameter was higher because the time at which $D T G_{\max }$ took place was longer. This low value could be due to the higher amount of impurities in this waste, that could make oxygen diffusion and heat transfer difficult [28], delaying the combustion times and producing a higher residual mass after combustion. Additionally, according to ash content results in Table 1, as well as the residual mass in Table 4, it might be concluded that Ma4 waste is not the most suitable residue for combustion.

According to the values obtained for $D_{i}$ and $S$, it was found that Ma3 and Ma4 had better ignition and combustibility properties, and therefore it can be said that, from that point of view, the wastes containing corn stalk were better than those containing corncob waste, as corncob waste had better characteristics when it was combined with leaves. On the other hand, regarding $D$ and $D_{f}$ values, a better behavior for Ma1 and Ma2 was found, that is, the wastes with higher amounts of corncob waste, and in the case of $\mathrm{Ma} 2$, there was a considerable improvement (therefore the presence of leaves promoted combustion).

In Figure 6, the graphical representation of the comparison of the combustion indexes is included, indicating the relative percentage with respect to the highest value obtained for each index. In this figure, the residue with the best combustion performance appears on the outside, whereas the residue with the worst characteristics appears in the innermost part of the geometric figure. The graph clearly showed the best combustibility characteristics for Ma3 when $D_{i}$ and $S$ indexes are observed; on the other hand, the $D$ and $D_{f}$ indexes showed better performance for the Ma2 residue.

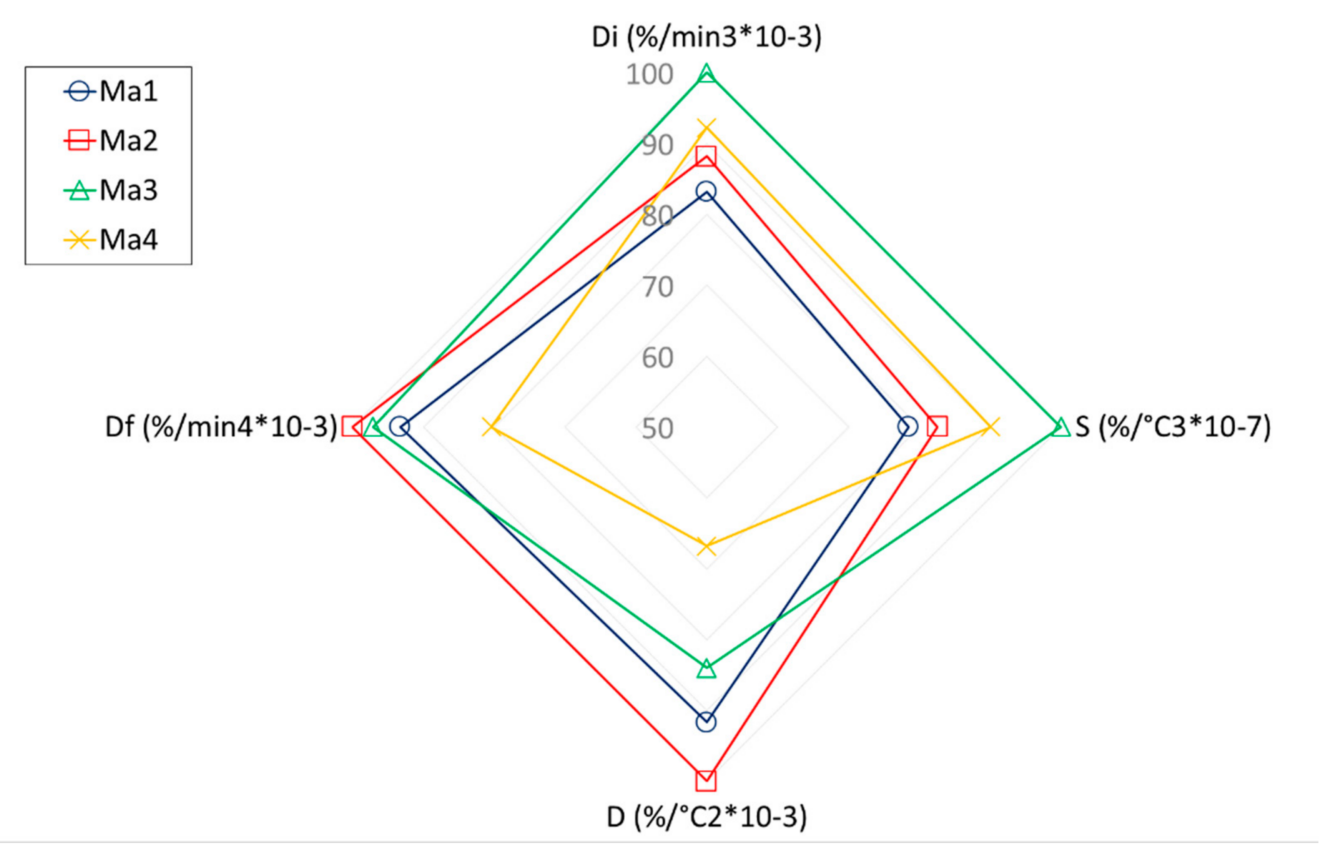

Figure 6. Combustion indexes. 
Considering the above, for combustion, the wastes with a majority of corncob waste obtained lower ash contents. On the other hand, the wastes with corn stalk had improved combustibility characteristics, but this slight improvement did not compensate for the drawback related to the increase in ash content; consequently, the selective collection is equally recommended. Moreover, it was found that the separation of leaves from the corncob waste is not recommended, as it worsens the combustion process. Finally, the negative effect of the contact of corn stover with soil was proved, as the residue degraded and had higher amounts of impurities, especially if it was converted to bales.

\section{Conclusions}

The most relevant findings of this study were the following:

- It can be inferred, from the characterization of the residues, that the moisture content was suitable for subsequent pelletizing without any previous drying process (less than $15 \%)$.

- Regarding ash content, all the residues were suitable for pellet production (A class) except for Ma4 residue, which was collected on the soil and showed a high ash content $(9.68 \%)$. This fact pointed out that the contact with the soil had a negative effect on the subsequent valorization of the waste. Therefore, direct collection by harvesting machines is desirable.

- The heating values are within the optimum range established by the corresponding quality standard for pelletizing (more than $16 \mathrm{MJ} / \mathrm{kg}$, dry basis).

- Concerning ash composition, $\mathrm{SiO}_{2}$ and $\mathrm{K}_{2} \mathrm{O}$ values imply a possible low ash melting point, which would be interesting to check through combustion tests of the residues.

- With regard to the pyrolysis process, optimum characteristics were observed for corncob waste or samples with the majority of its content containing this residue (Ma1 and Ma2); no significant difference was found in the presence of leaves. In this case, the selective collection of residues was highly recommended. Moreover, the direct collection by harvesting machines (without any contact between residues and soil) was advisable, as the subsequent degradation produced unfavorable results in pyrolysis.

- Concerning the study of combustion process, better characteristics were observed when corncob waste and corn stalk were combined. On one hand, the wastes with a majority of its content containing corncob waste obtained lower ash content. On the other hand, the wastes with corn stalk had improved combustibility. In any case, the negative effect of the degradation of the waste collected on the soil can be observed.

Therefore, it can be said that corn residues are a suitable biomass product that have an optimum behavior for energy use, that is, pellet production for domestic use, pellets for industrial use, direct electricity production or other thermal uses that can imply a valorization of corn crops. The results obtained pointed out the importance of the collection of the wastes by the time of their generation, avoiding contact with soil, as this would considerably worsen the thermal properties, especially for the subsequent densification at a small-scale, which would be the most profitable application for corn growers. Regarding the selective collection of wastes, it is highly advisable that, if the subsequent thermal use is going to be a pyrolytic process, not to require the removal of leaves, as better behavior was found for the separated corncob waste. In the case of combustion, although the samples with stalks improved the combustibility characteristics, this slight improvement did not compensate for the drawback related to the increase in ash content, especially for their use in small facilities. Consequently, selective collection is equally recommended.

Author Contributions: Conceptualization and methodology, M.T.M. and R.G.-M., investigation, M.T.M., R.G.-M., J.I.A., F.J.S., P.R. and A.B.-J.; writing—original draft preparation, R.G.-M.; writingreview and editing, M.T.M., R.G.-M. and J.I.A.; supervision, M.T.M., J.I.A. All authors have read and agreed to the published version of the manuscript. 
Funding: This research was funded by Junta de Extremadura and FEDER (Fondo Europeo de Desarrollo Regional "Una manera de hacer Europa") for its support through the economic aid for the project Application of the concept of circular economy to the management of bio-waste with limitations of use (IB18083), as well as research groups (GR18137, GR18057 and GR18035).

Institutional Review Board Statement: Not applicable.

Informed Consent Statement: Not applicable.

Conflicts of Interest: The authors declare no conflict of interest.

\section{References}

1. Food and Agriculture Organitation of the United Nations. FAOSTAT. 2020. Available online: http://fao.org/faostat/en/\#data (accessed on 1 September 2020).

2. Azuara, M.; Baguer, B.; Villacampa, J.; Hedin, I.; Manyà, J.J. Influence of pressure and temperature on key physico-chemical properties of corn stover-derived biochar. Fuel 2016, 186, 525-533. [CrossRef]

3. Zheng, J.; Choo, K.; Bradt, C.; Lehoux, R.; Rehmann, L. Enzymatic hydrolysis of steam exploded corncob residues after pretreatment in a twin-screw extruder. Biotechnol. Rep. 2014, 3, 99-107. [CrossRef] [PubMed]

4. Brutti, L.; Beltran, M. García de Salamone, Biorremediación de los Recursos Naturales; INTA Ediciones: Buenos Aires, Argentina, 2018.

5. Anwar, Z.; Gulfraz, M.; Irshad, M. Agro-industrial lignocellulosic biomass a key to unlock the future bio-energy: A brief review. J. Radiat. Res. Appl. Sci. 2014, 7, 163-173. [CrossRef]

6. Prasad, S.; Singh, A.; Joshi, H. Ethanol as an alternative fuel from agricultural, industrial and urban residues. Resour. Conserv. Recycl. 2007, 50, 1-39. [CrossRef]

7. Chen, Q.; Yang, R.; Zhao, B.; Li, Y.; Wang, S.; Wu, H.; Zhuo, Y.; Chen, C. Investigation of heat of biomass pyrolysis and secondary reactions by simultaneous thermogravimetry and differential scanning calorimetry. Fuel 2014, 134, 467-476. [CrossRef]

8. Shen, J.; Igathinathane, C.; Yu, M.; Pothula, A.K.; Cannayen, I. Biomass pyrolysis and combustion integral and differential reaction heats with temperatures using thermogravimetric analysis/differential scanning calorimetry. Bioresour. Technol. 2015, 185, 89-98. [CrossRef] [PubMed]

9. Berndes, G.; Abt, B.; Asikainen, A.; Cowie, A.; Dale, V.; Egnell, G.; Lindner, M.; Marelli, L.; Paré, D.; Pingoud, K.; et al. Forest biomass, carbon neutrality and climate change mitigation. In From Science to Policy 3; European Forest Institute: Joensuu, Finland, 2016. [CrossRef]

10. Arranz, J.I.; Miranda, M.T.; Montero, I.; Sepulveda, F.J.; Rojas, C.V. Characterization and combustion behaviour of commercial and experimental wood pellets in South West Europe. Fuel 2015, 142, 199-207. [CrossRef]

11. Zhang, G.; Sun, Y.; Shi, Y.; Jia, Y.; Xu, Y.; Zhao, P.; Zhang, Y. Characteristic and kinetics of corn stalk pyrolysis in a high pressure reactor and steam gasification of its char. J. Anal. Appl. Pyrolysis 2016, 122, 249-257. [CrossRef]

12. Aboyade, A.O.; Hugo, T.J.; Carrier, M.; Meyer, E.L.; Stahl, R.; Knoetze, J.H.; Görgens, J.F. Non-isothermal kinetic analysis of the devolatilization of corn cobs and sugar cane bagasse in an inert atmosphere. Thermochim. Acta 2011, 517, 81-89. [CrossRef]

13. Yang, X.; Zeng, Y.; Ma, F.; Zhang, X.; Yu, H. Effect of biopretreatment on thermogravimetric and chemical characteristics of corn stover by different white-rot fungi. Bioresour. Technol. 2010, 101, 5475-5479. [CrossRef]

14. Maddi, B.; Viamajala, S.; Varanasi, S.; Yuan, T.; Tahmasebi, A.; Yu, J. Comparative study of pyrolysis of algal biomass from natural lake blooms with lignocellulosic biomass. Bioresour. Technol. 2011, 102, 11018-11026. [CrossRef]

15. Gai, C.; Dong, Y.; Zhang, T. The kinetic analysis of the pyrolysis of agricultural residue under non-isothermal condi-tions. Bioresour. Technol. 2013, 127, 298-305. [CrossRef]

16. Kumar, A.; Wang, L.; Dzenis, A.; Jones, D.; Hanna, M.A. Thermogravimetric characterization of corn stover as gasification and pyrolysis feedstock. Biomass Bioenergy 2008, 32, 460-467. [CrossRef]

17. Li, Z.; Zhao, W.; Meng, B.; Liu, C.; Zhu, Q.; Zhao, G. Kinetic study of corn straw pyrolysis: Comparison of two different three-pseudocomponent models. Bioresour. Technol. 2008, 99, 7616-7622. [CrossRef]

18. Álvarez, A.; Pizarro, C.; García, R.; Bueno, J.L.; Lavín, A.G. Determination of kinetic parameters for biomass combus-tion. Bioresour. Technol. 2016, 216, 36-43. [CrossRef]

19. ISO. ISO 17225-6:2014. In Solid Biofuels. Fuel Specifications and Classes. Part 6: Graded Non-Woody Pellets; ISO: Geneva, Switzerland, 2014.

20. ISO. ISO 18134-2:2017. In Solid Biofuels. Determination of Moisture Content. Oven Dry Method. Part 2: Total Moisture. Simplified Method; ISO: Geneva, Switzerland, 2017.

21. ISO. ISO 17828:2015. In Solid Biofuels. Determination of Bulk Density; ISO: Geneva, Switzerland, 2015.

22. ISO. ISO 16948:2015. In Solid Biofuels. Determination of Total Content of Carbon, Hydrogen and Nitrogen; ISO: Geneva, Switzerland, 2015.

23. ISO. ISO 16994:2016. In Solid Biofuels. Determination of Content of Sulfur and Chlorine; ISO: Geneva, Switzerland, 2017.

24. ISO. ISO 18123:2016. In Solid Biofuels. Determination of the Content of Volatile Matter; ISO: Geneva, Switzerland, 2015.

25. ISO. ISO 18122:2015. In Solid Biofuels. Determination of Ash Content; ISO: Geneva, Switzerland, 2015.

26. ISO. ISO 18125:2017. In Solid Biofuels. Determination of Calorific Value; ISO: Geneva, Switzerland, 2017. 
27. Song, H.; Liu, G.; Zhang, J.; Wu, J. Pyrolysis characteristics and kinetics of low rank coals by TG-FTIR method. Fuel Process. Technol. 2017, 156, 454-460. [CrossRef]

28. Mureddu, M.; Dessì, F.; Orsini, D.; Ferrara, F.; Pettinau, A. Air- and oxygen-blown characterization of coal and biomass by thermogravimetric analysis. Fuel 2018, 212, 626-637. [CrossRef]

29. Moon, C.; Sung, Y.; Ahn, S.; Kim, T.; Choi, G.; Kim, D. Effect of blending ratio on combustion performance in blends of biomass and coals of different ranks. Exp. Therm. Fluid Sci. 2013, 47, 232-240. [CrossRef]

30. Lu, J.-J.; Chen, W.-H. Investigation on the ignition and burnout temperatures of bamboo and sugarcane bagasse by thermogravimetric analysis. Appl. Energy 2015, 160, 49-57. [CrossRef]

31. Paniagua, S.; Escudero, L.; Coimbra, R.N.; Escapa, C.; Otero, M.; Calvo, L.F. Effect of Applying Organic Amendments on the Pyrolytic Behavior of a Poplar Energy Crop. Waste Biomass Valoriz. 2018, 9, 1435-1449. [CrossRef]

32. Paniagua, S.; García-Pérez, A.I.; Calvo, L.F. Biofuel consisting of wheat straw-poplar wood blends: Thermogravimetric studies and combustion characteristic indexes estimation. Biomass Convers. Biorefin. 2018, 9, 433-443. [CrossRef]

33. Zhang, Y.; Guo, Y.; Cheng, F.; Yan, K.; Cao, Y. Investigation of combustion characteristics and kinetics of coal gangue with different feedstock properties by thermogravimetric analysis. Thermochim. Acta 2015, 614, 137-148.

34. Zhang, Y.; Ghaly, A.E.; Li, B. Physical Properties of Corn Residues. Am. J. Biochem. Biotechnol. 2012, 8, 44-53. [CrossRef]

35. Rony, A.H. Kinetics, thermodynamics, and physical characterization of corn stover (Zea mays) for solar biomass py-rolysis potential analysis. Bioresour. Technol. 2019, 284, 466-473. [CrossRef]

36. Wang, C.; Wang, F.; Yang, Q.; Liang, R. Thermogravimetric studies of the behavior of wheat straw with added coal dur-ing combustion. Biomass Bioenergy 2009, 33, 50-56. [CrossRef]

37. Vassilev, S.V.; Baxter, D.; Andersen, L.K.; Vassileva, C.G. An overview of the composition and application of biomass ash. Part 1. Phase-mineral and chemical composition and classification. Fuel 2013, 105, 40-76. [CrossRef]

38. Vassilev, S.V.; Baxter, D.; Andersen, L.K.; Vassileva, C.G. An overview of the composition and application of biomass ash. Fuel 2013, 105, 19-39. [CrossRef]

39. Rodríguez, J.L.; Álvarez, X.; Valero, E.; Ortiz, L.; De La Torre-Rodríguez, N.; Acuña-Alonso, C. Influence of ashes in the use of forest biomass as source of energy. Fuel 2021, 283, 119256. [CrossRef]

40. Diblasi, C. Modeling chemical and physical processes of wood and biomass pyrolysis. Prog. Energy Combust. Sci. 2008, 34, 47-90. [CrossRef]

41. Yang, Z. Combustion behaviours of tobacco stem in a thermogravimetric analyser and a pilot-scale fluidized bed reac-tor. Bioresour. Technol. 2012, 110, 595-602. [CrossRef] [PubMed]

42. Parshetti, G.K.; Quek, A.; Betha, R.; Balasubramanian, R. TGA-FTIR investigation of co-combustion characteristics of blends of hydrothermally carbonized oil palm biomass (EFB) and coal. Fuel Process. Technol. 2014, 118, 228-234. [CrossRef] 